\title{
MEMPREDIKSI DAN MENGANALISA PENJUALAN PT. MITRA ASIA SYNERGY DENGAN METODE REGRESI LINEAR
}

\author{
${ }^{1}$ Hermawan Andhi Prastyo, ${ }^{2}$ Shinta Estri Wahyuningrum \\ ${ }^{1,2}$ Program Studi Teknik Informatika Fakultas IImu Komputer, Universitas Katolik Soegijapranata \\ 12i3.andhii@gmail.com, 22shinta@unika.ac.id
}

\begin{abstract}
The problem in this project is about exporter's inventories which is certainly very difficult to prepare the goods that every month. If one provides goods inventory, it will increases the sale of goods. Also the types of goods sold are varied, making it difficult to manage how much inventory space must be prepared for one type of item. For this reason, it requires sales prediction per item in order to estimate inventory of goods that must be prepared. The predictions method used was Linear Regression. In addition, statistical approaches are needed to analyze inventory. With these two methods, it will facilitate decision making for inventory items to be prepared. The final result of this project is to implement a model to predict inventory good that needed to be added and test how accurate the results of predictions are with actual data.
\end{abstract}

Keywords: Linear Regression, Statistics, Export

\section{Pendahuluan}

Di negara manapun tidak terlepas dari aktifitas perdagangan dengan negara lain, seiring perkembangannya tiap Negara memilik komoditas andalan untuk diperdagangkan dengan Negara lain. Oleh sebab itu para eksportir melakukan perhitungan terhadap barang dagangannya ke negara lain. Karena setiap eksportir belum tentu menggambil jumlah barang dagangannya yang sama ke setiap Negara. Oleh sebab itu, para eksportir harus memperhitungkan jumlah barang yang di ekspor ke setiap Negara agar terpenuhi.

Banyaknya permintaan setiap negara, Sulitnya eksportir menyediakan jumlah barang yang diekspor kepada customer setiap bulannya. Karena kurangnya persediaan barang yang mengakibatkan menurunnya tingkat ekspor terhadap beberapa negara, dan membuat reputasi yang kurang baik terhadap eksportir dan sulit nya menemukan eksportir baru.

Metode Regresi linear digunakan untuk pemodelan hubungan antara satu variabel dependen dan satu variabel independen, dalam hubungan antara variabel bersifat linear, dimana perubahan pada variabel faktor penyebab $\mathrm{X}$ akan diikuti oleh perubahan pada variabel akibat $\mathrm{Y}$ secara tetap. Dan menggunakan Statistika untuk menganalisa penjualan ekspor yang dilihat dari penjualan perbulan, rata-rata penjualan, penjualan barang sering di beli konsumen, dan penjualan terbanyak selama 1 tahun.

Berdasarkan masalah diatas maka project ini menggunakan Metode regresi linear. Regresi linear digunakan untuk memprediksi jumlah barang yang diperlukan di setiap Negara dengan metode yang sesuai dengan kebutuhan customer. Statistika digunakan untuk menganalisa penjualan barang yang diperlukan di setiap negara dan kebutuhan customer. Yang dapat digunakaan untuk memproses data yang diberikan dari hasil inputan ke dalam aplikasi. 


\section{LANDASAN TEORI}

Iman Mustofa Kamal, Tachbir Hendro dan Ridwan Iiyas dalam penelitian ini membahas "Prediksi Penjualan Buku Menggunakaan Data Mining Di PT. Niaga Swadaya" [1]. Jurnal ini membahas permasalahan penjualan buku yang tidak mencapai target yang sangat merugikan perusahaan dengan hal tersebut [1]. Menimbulkan dampak negatif terhadap pembayaran sewa, pemberian gaji karyawan dan kebutuhan untuk produksi yang akan terhambat.

Maria Krisnawati dan Niko Siameva Uletika dalam penelitian ini membahas "Peramalan Jumlah Ketersediaan Bahan baku Industri Gula Kelapa Kabupaten Purbalingga Dengan Metode Regresi Linear" [2]. menjelaskan tentang produk gula kristal yang merupakan pengembangan dari produk gula kelapa kabupaten purbalingga yang telah dapat mengekspor produknya ke negara jepang [2].

M. Syafruddin, Lukmanul Hakim dan Dikpride Despa dalam penelitian ini membahas "Metode Regresi Linier untuk Prediksi Kebutuhan Energi Listrik Jangka Panjang (Studi Kasus Provinsi Lampung)" [3]. Regresi linear adalah upaya untuk memprediksi sebuah output yang berbentuk bilangan kontinu [4]. Jurnal ini membahas permasalahan sistem kelistrikan di provinsi lampung yang masih memerlukan suplai listrik dari sumatera selatan [3]. Namun di tahun-tahun yang akan datang suplai listrik dari sumatera selatan diharapkan dapat dikurangi.

Reni Untarti dan Fitrianto Eko Subekti dalam penelitian ini membahas "Deskripsi Kemampuan Representasi Matematis Ditinjau Dari Permintaan Jenjang Pendidikan Menengah Mahasiswa Program Studi Pendidikan Matematika Pada Mata Kuliah Statistika Deskriptif” [5]. Menjelaskan penelitian ini meliputi tiga tahapan utama yaitu: tahapan persiapan, tahapan pelakasanaan, dan tahapan analisa data. Pada tahapan persiapan meliputi: mempersiapkan soal yang mengukur kemampuan representasi matematis, menentukan subyek penelitian, yaitu dengan cara purposive sampling, sehingga diperoleh 9 mahasiswa dari jenjang SMK teknik untuk diwawancarai tentang kemampuan representasi matematisnya, dan membuat pedoman wawancara [5].

Ponti Panggabean dalam penelitian ini membahas "Peranan Penjualan Pribadi Dalam Meningkatkan Volume Penjualan Pada PT. Indako Trading Co. Medan” [6]. Menjelaskan tentang penjualan sepeda motor PT. Indako Trading Co. Medan dengan adanya sistem individu untuk menarik para calon konsumen dan diharapkan terjadi suatu hubungan atau interaksi positif antara pengusaha dan konsumen. Komunikasi yang dilakukan bersifat individual sehingga penjual dapat langsung memperoleh tanggapan tentang keinginan dan selera pembeli [6].

Kuntadi Widiyoko dan Iwan Setyawan dalam penelitian ini membahas "Perbanding Penggunaan Mean, Median dan Invarians Statistik Koefisien DCT Dalam Perancangan Image Hashing" [7]. memjelaskan bagaimana sistem Image hashing yang dirancang menjadi dua bagian. Bagian pertama perancangan menggunakan mean dan median. Untuk bagian kedua perancangan menggunakan statical invariance koefisien DCT. Dari perancangan tersebut dapat memasukan nilai mean dan nilai median yang akan dibandingkan agar mendapatkan nilai bit hash. Bila nilai mean 
lebih besar dari nilai mean akan memperoleh nilai bit hash sama dengan satu, sedangkan nilai median lebih kecil dari pada nilai median akan memperoleh bit hash sama dengan nol [7].

Anis setiyawati dalam penelitian ini membahas "Analisis pengaruh PAD, DAU, DAK, Dan Belanja Pembangunan Terhadap Pertumbuhan ekonomi, Kemiskinan, dan Pengangguran” [8]. Menjelaskan menggenai perbedaan kesenjangan antara kabupaten dan kota yang menerima PAD, DAU dan DAK. Yang menentukan perbedaan berdasarkan nilai minimum, maksimum, mean dan standar deviasi. Dengan hasil pengujian secara langsung dengan standar deviasi menunjukkan PAD berpengaruh secara positif terhadap pertumbuhan ekonomi, sedangkan DAU berpengaruh negatif terhadap pertumbuhan ekonomi, terhadap kemiskinan dan pengangguran menunjukkan adanya pengaruh yang signifikan, tetapi pertumbuhan ekonomi berpengaruh negatif terhadap kemiskinan dan berpengaruh positif terhadap pengangguran [8].

M. Hakiki Oceandra dalam penelitian ini membahas "Pengurangan Noise Pada Citra Digital Menggunakan Metode Statistik Mean, Median, kombinasi dan Rekursif filter" [9]. Menjelaskan tentang metode statistik dapat digunakan untuk melakukan pengurangan noise dengan menggunakan metode statistik mean, median, rekursif dan kombinasi. Untuk menggurangi impulse noise yang terbaik dengan menggunakan median filter. Semakin tinggi intensitas noise, penggunaan filter median secara rekursif maupun kombinasi yang akan memberikan hasil yang lebih baik [9].

Yuliana Maesa Putri dalam penelitian ini membahas "Pengaruh Dukungan Politik, Pendapatan Daerah Periode jabatan dan belanja daerah terhadap Budget Forecast Error Pemerintah daerah di sumatera" [10]. Menjelaskan tentang pemerintahan daerah perlu meningkatkan transparansi dalam penetapan APBD sehingga anggota legislatif baik yang berasal dari partai pendukung kepala daerah maupun tidak berasal dari partai pendukung kepala daerah dapat lebih terawasi dan meminimalkan terjadinya fraud yang dapat berakibat buruk pada kinerja pemerintah daerah [10].

\section{Metodologi Penelitian}

\section{Journal Study}

Jurnal yang digunakaan sebagai acuan agar project ini berjalan sesuai harapan. Rumus perhitungan berdasarkan dari jurnal tersebut, oleh karena itu proses penelitian ini menggunakan metode regresi linear dan statistik untuk memprediksi penjualan ekspor dan menganalisa penjualan ekspor supaya perusahaan tidak terlalu banyak menyediakan barang yang akan di ekspor bila barang yang di ekspor kurang di minati oleh customer. Dengan mendapatkan referensi dari jurnal tersebut. Maka memudahkan pembuatan program yang sesuai dengan keperluan.

\section{Problem Analysis}

Project ini mengidentifikasi masalah yang akan diselesaikan melalui program yang dibuat. Batasan-batasan yang sudah dibuat akan diselesaikan sesuai tanggal dan waktu yang disepakati 


\section{Data Collection and Coding Process}

Data yang digunakan untuk project ini adalah data penjualan PT. Mitra Asia Synergy pada bulan januari sampai desember tahun 2017. data yang didapat akan dimasukan kedalam rumus dan dimasukan ke dalam logika program. Dengan itu data yang telah didapat akan di olah menjadi CSV dan menggunakan bahasa pemprograman PHP.

\section{Research Report}

Project ini menggunakaan metode regresi linear untuk memprediksi penjualan barang expor dan menganalisa dengan met Statistik meliputi perhitungan mean yang dihitung dengan cara,

$$
\bar{x}=\frac{\sum x}{n}
$$

median seperti yang dihitung dengan cara,

$$
\mathcal{M}=\frac{n}{2}
$$

modus, standar deviasi (3), dengan masing - masing rumus sebagai berikut,

$$
S=\sqrt{\frac{\sum(x-\bar{x})^{2}}{n-1}}
$$

Untuk melakukan regresi linear, beberapa fungsi seperti koefisen regresi yang dihitung dengan cara sebagai berikut,

$$
B=\frac{n \sum X Y}{n \sum X^{2}}-\frac{\left(\sum X \cdot \sum Y\right)}{(X)^{2}}
$$

fungsi untuk mencari konstanta yang dihitung dengan cara sebagai berikut,

$$
A=\frac{\sum Y-B \sum X}{n}
$$

fungsi untuk mencari perhitungan prediksi,

$$
Y=A+B \cdot X
$$

fungsi untuk mencari RMSE,

$$
R M S E=\sqrt{\frac{\sum(X-f)^{2}}{n}}
$$

\section{Hasil Akhir Data}

Data yang sudah diolah menggunakan metode regresi linear. Menghasilkan prediksi penjualan barang ekspor yang dilihat berdasarkan data diagram penjualan ekspor pada bulan sebelumnya. 


\section{Hasil dan Pembahasan}

\section{Analisis}

Proses ujicoba program dengan melakukan dua kali percobaan menganalisa sub total penjualan barang ekspor.

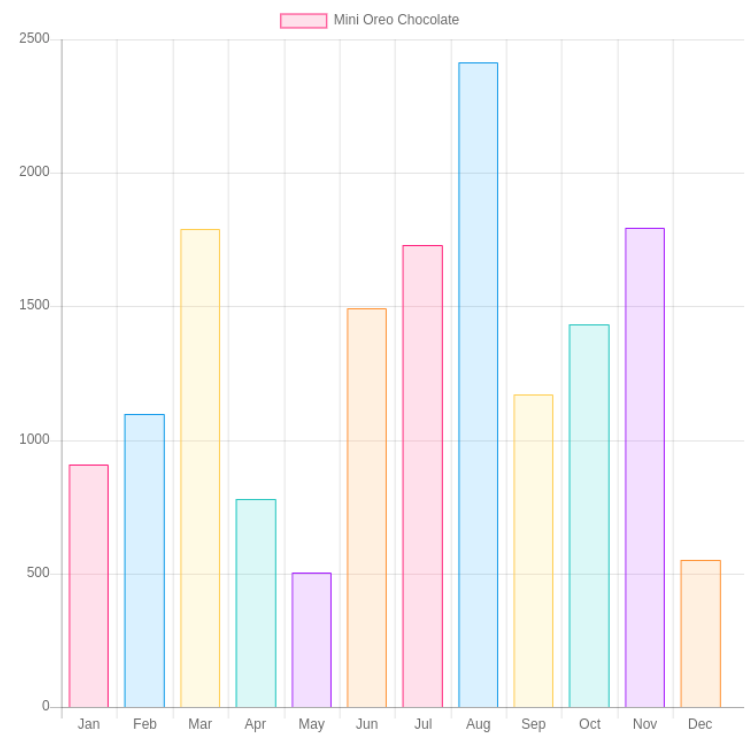

Gambar 1. Analisa Penjualan Mini Oreo Chocolate

Pada Gambar 1 Ujicoba yang pertama dengan menggunakan item mini oreo chocolate dan menbuat sub total dari item tersebut, yang sesuai dengan inputan data program. Dari grafik tersebut dapat menganalisa penjualan item mini oreo chocolate yang paling sering dibeli pada bulan. Maret, Juli, Agustus, November.

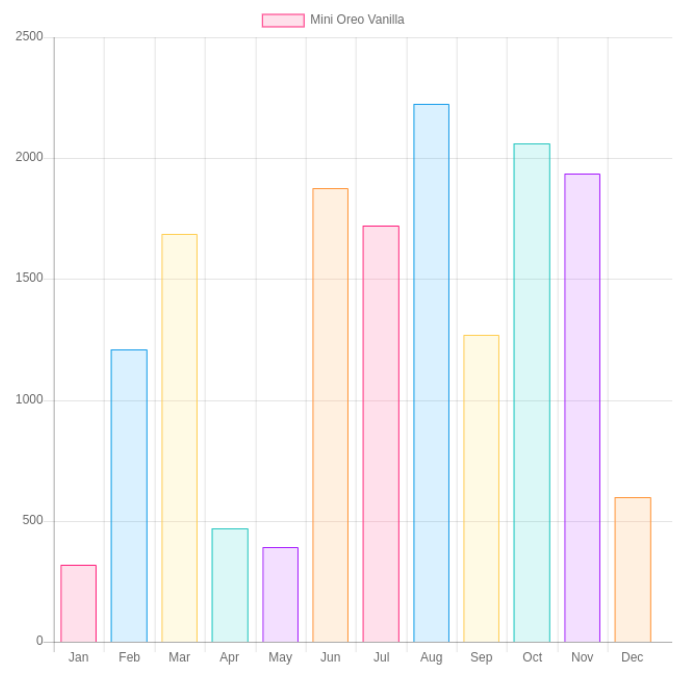

Gambar 2. Analisa Penjualan Mini Oreo Vanilla 
Pada Gambar 2 Ujicoba yang kedua dengan menggunakan item mini oreo vanilla dan menbuat sub total dari item tersebut, yang sesuai dengan inputan data program. Dari grafik tersebut dapat menganalisa penjualan item mini oreo vanilla yang paling sering dibeli pada bulan. Juni, Agustus, oktober, november.

Proses uji program dengan melakukan dua kali percobaan menggunkan data dari bulan januari sampai bulan juni dan diteruskan dengan bulan juni sampai bulan desember. Data yang digunakan adalah data penjualan expor PT. Mitra Asia Synergy.

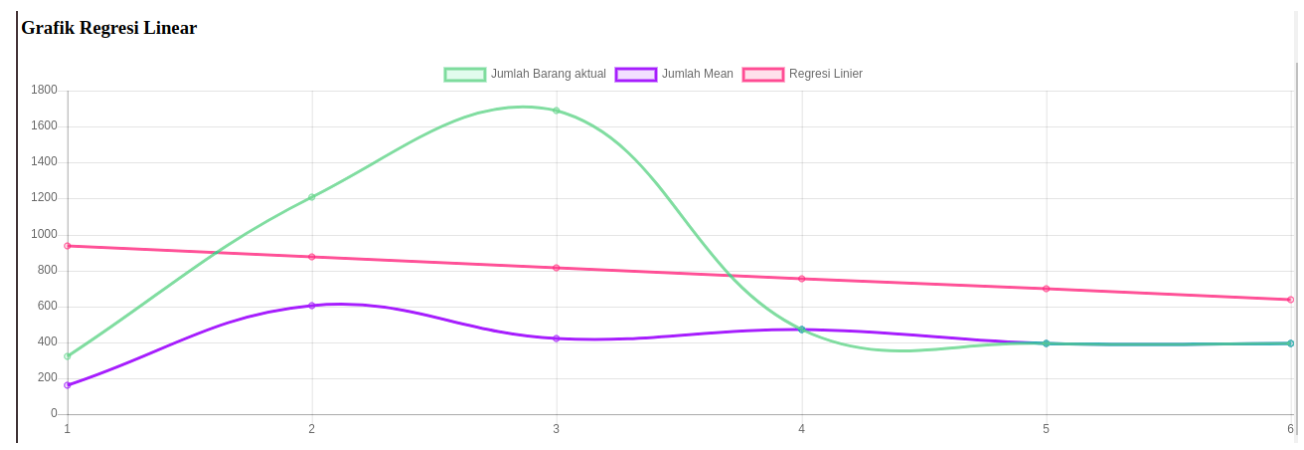

Gambar 3. Percobaan Bulan Januari Sampai Juni

Percobaan pertama dengan menggunakan item mini oreo vanilla dan data bulan januari sampai bulan juni. Dari grafik tersebut dapat dilihat RMSE 497.188 data bulan januari sampai juni menurun. Karena mencari customer baru dan adanya libur lebaran yang mengharuskan container dan mobil-mobil berat tidak boleh beroperasi diruas jalan utama dan jalan toll. Dapat dilihat di gambar 3 .

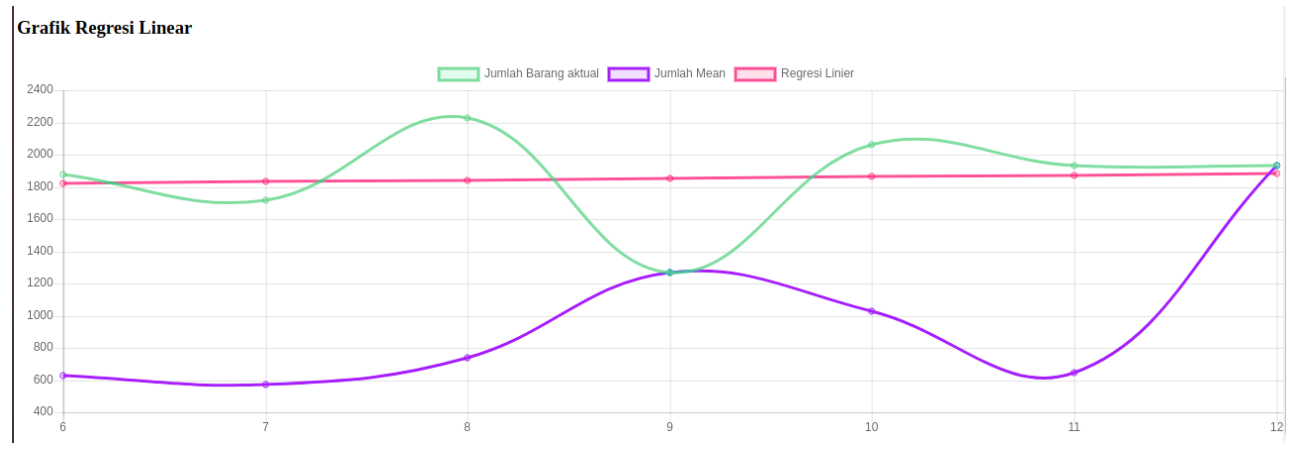

Gambar 4. Percobaan Bulan Juni Sampai Desember

Percobaan kedua dengan menggunakan item mini oreo vanilla dan data dari bulan juni sampai bulan desember. Dari grafik tersebut dapat dilihat RMSE 213.418 data bulan juni sampai desember mengalami kenaikan. Karena orderan yang sudah masuk dari customer baru dan customer rutin. Dapat dilihat pada gambar 4. 


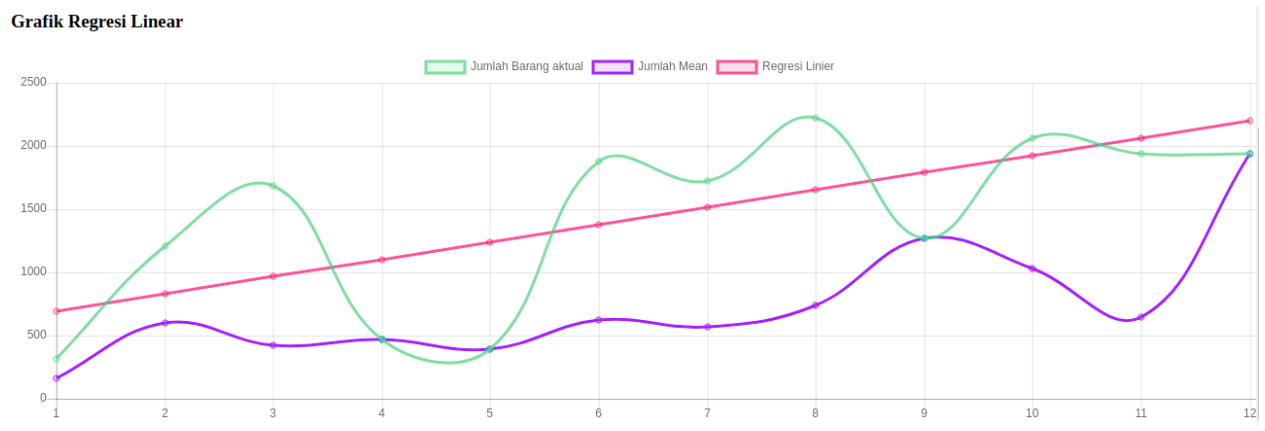

Gambar 5. Percobaan Bulan Januari Sampai Desember

Percobaan ketiga dengan menggunakan item mini oreo vanilla dan data dari bulan januari sampai bulan desember. Dari grafik tersebut dapat dilihat RMSE 492.907 Mengalami peningkatan yang sangat tinggi. Dapat dilihat di gambar 5.

\section{Desain}
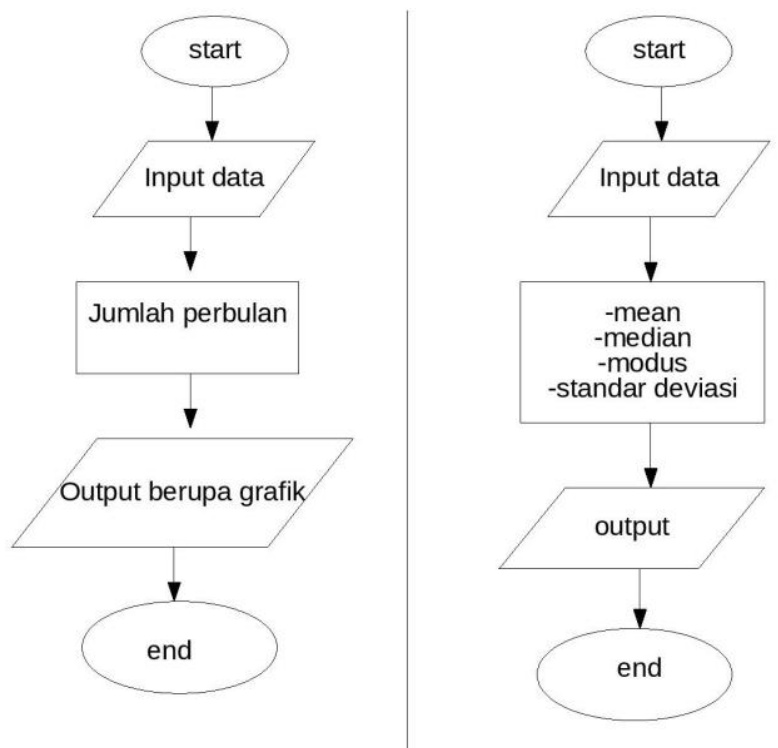

Gambar 6. Diagram alir

Dari gambar 6 diatas menjelaskan dua alur statistika. Pada alur statistika sebelah kiri menjelaskan menjumlah keseluruhan barang keluar. Langkah pertama memilih nama barang yang akan jumlah. Langkah berikutnya menampilkan jumlah barang yang keluar dari bulan Januari hingga bulan Desember. Langkah terakhir menampilkan grafik penjualan bulan januari sampai bulan desember. Grafik memudahkan untuk melihat penjualan per bulan, bisa mengetahui penjualan terbanyak dan paling sedikit. Juga memudahkan untuk melihat persediaan barang setiap bulanya dan menjadi acuan ketersediaan barang dibulan berikutnya. 
Pada alur statistika sebelah kanan menjelaskan rumus statistika dasar. Dengan langkah pertama memilih barang yang akan di proses menggunakan rumus statistika selama setahun. Langkah kedua menampilan nilai mean, modus, median, dan standar deviasi. Mean menghitung rata-rata penjualan item yang dipilih. Modus menampilkan jumlah penjualan dengan nilai yang sama. Median untuk mengetahui penjualan pada tengah periode. Sedangkan standar deviasi untuk mengetahui penjualan yang berada pada luar standar.

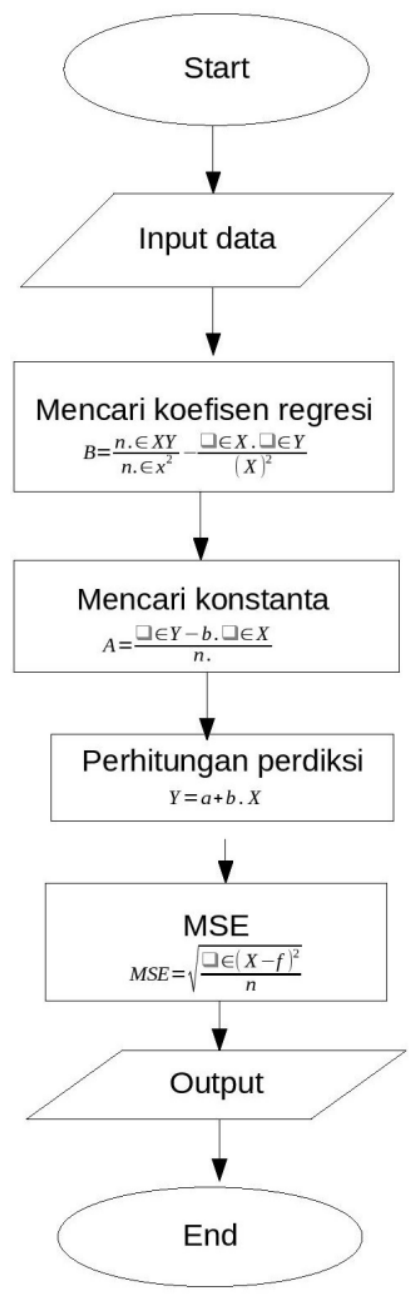

Gambar 7. Flowchart Regresi Linear

Pada gambar 7 menjelaskan langkah pertama menginput data berasal dari bulan dan nama item yang akan diprediksi. Bulan yang diinput minimal 5 bulan. Langkah awal pengolahan data dengan mencari koefisen dan konstanta. Koefisen dan konstanta, digunakan untuk memprediksi penjualan ekspor. Dari hasil Prediksi berisi penjualan dibulan berikutnya. Contoh mencari prediksi penjualan dibulan Juni. Maka input bulan Januari hingga bulan Mei. Dan memasukan item penjualan setiap bulannya. Terakhir menghitung keakurasian hasil prediksi dengan rumus RMSE yang berfungsi untuk memastikan hasil prediksi dengann data real. 


\section{KESIMPULAN}

Hasil dari ujicoba data dengan menggunakan item mini oreo vanilla dan data bulan januari sampai bulan juni, mengalami penurunan yang dapat dilihat dari tingkat keakuratan RMSE 497.188. sedangkan bulan juni sampai desember mengalami kenaikan yang dapat dilihat dari tingkat keakuratan RMSE 213.418. sedangkan bulan januari sampai bulan desember mengalami kenaikan yang dapat dilihat tingkat keakuratan RMSE 492.907 yang tinggi. Penyebab di bulan januari dan februari orderan sangat sedikit dikarenakan perusahan sedang mencari customer baru. Sedangkan mendekati akhir tahun mengalami kenaik yang dikarenakan customer baru dan customer lama sudah rutin melakukan order barang yang diekspor.

Untuk penelitian selanjutnya, dapat menganalisa data penjualan satu periode dengan menggunakan metode statistika. Metode statistika dapat mengetahui jumlah penjualaan barang expor dan mengetahui barang yang sangat diminati setiap customer.

\section{Daftar Pustaka}

[1] I. M. Kamal, T. H. P, and R. Ilyas, "PREDIKSI PENJUALAN BUKU MENGGUNAKAN DATA MINING DI PT. NIAGA SWADAYA," SEMNASTEKNOMEDIA ONLINE, vol. 5, no. 1, Art. no. 1, Feb. 2017.

[2] M. Krisnawati and N. S. Uletika, "RAMALAN JUMLAH KETERSEDIAAN BAHAN BAKU INDUSTRI GULA KELAPA KABUPATEN PURBALINGGA DENGAN METODE REGRESI LINIER,” Prosiding, vol. 7, no. 1, Art. no. 1, Nov. 2017, Accessed: May 15, 2021. [Online]. Available: http://jurnal.lppm.unsoed.ac.id/ojs/index.php/Prosiding/article/view/447

[3] M. Syafruddin, L. Hakim, and D. Despa, "METODE REGRESI LINIER UNTUK PREDIKSI KEBUTUHAN ENERGI LISTRIK JANGKA PANJANG (STUDI KASUS PROVINSI LAMPUNG)," Jurnal Informatika dan Teknik Elektro Terapan, vol. 2, no. 2, Art. no. 2, Apr. 2014, Accessed: May 15, 2021. [Online]. Available: https://journal.eng.unila.ac.id/index.php/jitet/article/view/237

[4] J. W. G. Putra, Pengenalan Pembelajaran Mesin dan Deep Learning. 2020.

[5] R. Untarti and F. E. Subekti, "Deskripsi kemampuan representasi matematis ditinjau dari peminatan jenjang pendidikan menengah mahasiswa program studi pendidikan matematika pada mata kuliah statistika deskriptif," Jurnal Mercumatika: Jurnal Penelitian Matematika dan Pendidikan Matematika, vol. 2, no. 2, pp. 15-32, Apr. 2018, doi: 10.26486/jm.v2i1.299.

[6] Ponti Panggabean, "Peranan Penjualan Pribadi dalam Meningkatkan Volume Penjualan pada PT. Indako Trading Co. Medan,” Jurnal Ilmiah Methonomi, vol. 2, no. 2, 2016.

[7] K. Widiyoko and I. Setyawan, "Perbandingan Penggunaan Mean Lokal, Median Lokal dan Invarians Statistik Koefisien DCT dalam Perancangan Image Hashing," Techné: Jurnal Ilmiah Elektroteknika, vol. 13, no. 02, Art. no. 02, Oct. 2014.

[8] A. Setiyawati and A. Hamzah, "ANALISIS PENGARUH PAD, DAU, DAK, DAN BELANJA PEMBANGUNAN TERHADAP PERTUMBUHAN EKONOMI, KEMISKINAN, DAN PENGANGGURAN: PENDEKATAN ANALISIS JALUR," Jurnal Akuntansi dan Keuangan Indonesia, vol. 4, no. 2, Art. no. 2, Dec. 2007, doi: 10.21002/jaki.2007.11. 
[9] M. H. Oceandra, "PENGURANGAN NOISE PADA CITRA DIGITAL MENGGUNAKAN METODE STATISTIK MEAN, MEDIAN, KOMBINASI DAN REKURSIF FILTER.”

[10] Y. M. Putri, "Pengaruh Dukungan Politik, Pendapatan Daerah, Periode Jabatan Dan Belanja Daerah Terhadap Budget Forecast Errors Pemerintah Daerah Di Sumatera," Jurnal Akuntansi, vol. 6, no. 1, Art. no. 1, Feb. 2018, Accessed: May 15, 2021. [Online]. Available: http://ejournal.unp.ac.id/students/index.php/akt/article/view/2767 